

\title{
Using a Bio-Psycho-Social Approach for Students With Severe Challenging Behaviours
}

\author{
Lisa Reisinger, West Montreal Readaptation Centre
}

\begin{abstract}
What teachers learn about classroom management in education classes often results in behaviour strategies that do not account for the individuality of each student. Teachers would benefit greatly from a common formula for effective problem solving and decision making with regard to choosing when to use the strategies in their "tool box." The solution proposed is the building of an individual biopsychosocial, multimodal profile for each student with chronic challenging behaviours.
\end{abstract}

\section{A Flexible Strategy for Successful Classroom Management}

magine for a moment that a classroom can be compared to the creation of a saltwater fish tank, with all of the delicate needs of the different salt-water fish in a single tank. Preserving and maintaining this fragile environment would require specific knowledge of the individual needs of the various types of fish, along with an understanding of the required elements or resources that each fish, such as coral reefs, crustaceans, saltwater plants, anemones, specific kinds of water filtration, and carefully considered water chemistry. After all of the environmental "engineering," a marine ecosystem would be created that would require constant monitoring for problems and a quick response time for modifications in order for the fish to remain alive. Only a devoted aquarist, who considered the individual needs of each fish, could manage a salt-water tank that includes both hardy fish as well as delicate fish with special aquarium needs. 
Keeping that example in mind, today's classrooms are replete with learners whose diverse nature is reflected by differences in their cultural, cognitive, developmental, linguistic, preexisting knowledge, and learning preferences needs. Implementing differentiated instruction can seem near impossible because addressing learning needs is often overshadowed by problem behaviour in the classroom. With the wrong classroom dynamics, challenging behaviours can often take up the majority of teachers' time. Effective teaching practices must include using effective classroom management procedures that respect students' diverse needs, while concurrently promoting student engagement and motivation. This kind of outstanding expectancy of teachers requires a solid plan that can withstand even the most difficult of students. The formula described below is set within the framework of differentiated instruction but uses a biopsychosocial, multimodal approach leading to a precise functional behaviour analysis that can, in turn, be relied on by teachers and specialized educators alike.

\section{The Components}

- Implementation of a biopsychosocial multimodal plan (Griffiths, Gardner, \& Nugent, 1998) for all chronically inflexible children

- Individualized problem solving for solutions to difficult behaviour by using a functional behaviour analysis that is based on the multimodal plan. Decisions are made based on why the behaviour is occurring or what is maintaining the behaviour

- The continued pursuit of professional development opportunities to maintain a "tool box" of currently advised, evidence-based strategies for diverse and difficult students

\section{The Biopsychosocial Multimodal Plan Adapted for Teachers}

The biopsychosocial model was coined by Roy Grinker in the 1950s (a neurologist and psychiatrist; see also Grinker, 1964) and later applied to general medicine by Dr. George Engel, a specialist of functional gastrointestinal disorders. Engel was considered to be the founder of this approach. The biopsychosocial approach (Engel, 1977, 1980) was designed to consolidate interacting components from three fields into the assessment and treatment of medical health problems by emphasizing the importance of understanding human health in a holistic context. Using a biopsychosocial perspective, complex behaviour can be considered as a result of multiple causes. This model was intended as a general health care delivery model but is used most often 
by psychiatrists and developmental psychologists because of its humanistic approach. This model takes into consideration the complex nature of individuals and, with minor modification, is a perfect tool for teachers who are on the front lines of behaviour interpretation in the classroom. The biopsychosocial approach provides the foundation for accurate functional behaviour analysis-the only evidence-based method of analyzing difficult behaviour.

The bio-psycho-social approach systematically considers biological, psychological, and social/environmental factors, alongside their complex interactions. Biological/ medical type factors include medical, psychiatric, and neurological states that can cause behaviour. Psychological factors include current psychological features (i.e., emotional, cognitive, developmental) as well as skill deficits that can influence how a student behaves. The social/environmental factors include family, cultural, interpersonal, school program factors, and physical aspects of the environment that can affect behaviour (Griffiths \& Gardner, 2002). In order to predict behaviour outcomes and influence future behaviour, an understanding of the following is required: 1) the synthesis of instigating conditions, such as the social/environmental causes of the behaviour, 2) the child's vulnerabilities (psychological/biological/medical factors inherent in the child), and 3) the reinforcing (maintaining) factors that can influence challenging behaviour. Gaining this complex understanding of behaviour is a multifaceted task, which requires a purposeful multimodal approach to the assessment and treatment of difficult behaviours.

Using an integrated biopsychosocial approach for mapping a child's behaviour profile is referred to as the multimodal profile (Griffiths et al., 1998). The multimodal profile is based on the assumptions that not only are the individual contributions of each component significant (i.e., the biological, psychological, and social/environmental components), but the interaction between components also plays a critical role in understanding why behaviour occurs. A comprehensive treatment plan is based upon what is known about the component interactions, and is the result of completing a multimodal profile grid for an individual. (Refer to Tables 1, 2, and 3 for a sample profile). The discussion below posits that teachers would benefit greatly from an understanding and the use of a modified multimodal approach for difficult-to-manage students. 


\section{Components of the Multimodal Profile for a Student With Challenging Behaviours}

Instigating conditions or precipitating factors. These factors, which result in the occurrence of challenging behaviour, may include aspects of the school, social, or physical environment (social/environmental factors) (Griffiths \& Gardner, 2002). These conditions may act as triggering factors (antecedents) in that they precede the challenging behaviour. For example, let's hypothetically consider Adam* (*pseudonym), a student who is highly sensitive to sound. Adam may always react with challenging behaviours if the classroom is too noisy. Alternatively, other factors may act as contributing conditions in that they would not trigger the behaviour in isolation. Instead, they will increase the likelihood of the behaviour when several of the conditions have been combined. For example, Adam may also be affected by contributing factors. He may appear irritable or uncomfortable when these contributing conditions occur in isolation, but will only display challenging behaviours if several of the contributing conditions are combined. Specifically, if Adam is requested to complete a visually "busy" worksheet while he is fatigued and is sitting too close to another student, he may act out by hitting the student. If Adam arrives at school tired (his profile in Table 2 indicates periodic insomnia) but no other contributing conditions are present, Adam may work more slowly or appear uncomfortable, but will not display the hitting behaviours.

Other social/environmental features may include mismatches between the individual and the physical environment, (e.g., sensitivity to temperature, light, or seating conditions), the social environment (e.g., sensitivity to personality types or working in groups) or related to the school program (e.g., sensitivity to the amount of work requested, presentation of work, or level of difficulty of work). Refer to Table 1 as follows for a full description of Adam's instigating conditions related to social/ environmental factors. 


\section{Table 1}

\section{Sample Multimodal Profile for Instigating Conditions}

\section{(Triggering and Contributing Factors)}

\begin{tabular}{|c|c|c|c|}
\hline \multicolumn{4}{|c|}{ Name of Student: Adam } \\
\hline \multirow{2}{*}{\multicolumn{2}{|c|}{$\begin{array}{l}\text { Behaviours Targeted: } \\
\text { 1) Hitting } \\
\text { 2) Screaming } \\
\text { 3) Throwing objects }\end{array}$}} & \multicolumn{2}{|l|}{ Instigating Conditions } \\
\hline & & $\begin{array}{l}\text { Triggering Factors } \\
\text { (Always an antecedent) }\end{array}$ & $\begin{array}{l}\text { Contributing Factor } \\
\text { (Antecedents when combined) }\end{array}$ \\
\hline \multirow{3}{*}{ 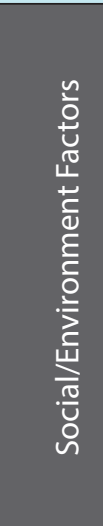 } & Physical Environment & $\begin{array}{l}\text { - Not having a work break } \\
\text { every } 10 \text { minutes during } \\
\text { seated work } \\
\text { - Classroom too noisy }\end{array}$ & $\begin{array}{l}\text { Having to concentrate } \\
\text { while being physically } \\
\text { close to another student } \\
\text { (other student becomes } \\
\text { a distraction) }\end{array}$ \\
\hline & Social Environment & $\begin{array}{l}\text { - Working with loud or } \\
\text { forceful students }\end{array}$ & $\begin{array}{l}\text { - Working in groups of more } \\
\text { than two } \\
\text { - Tolerating other students } \\
\text { when fatigued }\end{array}$ \\
\hline & School Program & $\begin{array}{l}\text { - Work is too difficult } \\
\text { - If he perceives that he will } \\
\text { not do well on a test or an } \\
\text { assignment, he will act out }\end{array}$ & $\begin{array}{l}\text { - Worksheet is too visually } \\
\text { busy } \\
\text { - Not having a calculator } \\
\text { during math period }\end{array}$ \\
\hline
\end{tabular}

Modified from the Multimodal Contextual Behavior Analytic Worksheet: D.M Griffiths, W.I Gardner, \& J.A. Nugent (1998). Behavioral supports: Individual centered interventions - A multimodal functional approach. Kingston, NY: NADD Press.

Vulnerability conditions, or risk factors. These conditions may include features of the individual (psychological or biological/medical factors) that place the individual at risk for problem behaviour. Vulnerability conditions may include skill deficits (e.g., poor expressive language or rote memory), cognitive deficits, psychological features (e.g., social anxiety, fear of failure), biological abnormalities (e.g., sensory sensitivities or difficulty sleeping), or medical/mental health diagnoses (e.g., epilepsy, ADHD, or autism). Vulnerability conditions increase the likelihood of challenging behaviour in the classroom. 
Table 2

\section{Sample Multimodal Profile for Vulnerability Conditions}

(Psychological and Biological/Medical Factors)

\begin{tabular}{|c|c|c|}
\hline \multicolumn{3}{|c|}{ Name of Student: Adam } \\
\hline \multirow{3}{*}{ 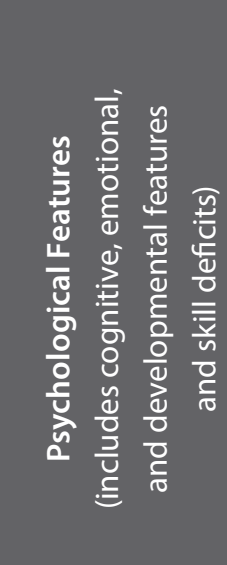 } & \multicolumn{2}{|c|}{ Vulnerability Conditions } \\
\hline & Presenting Features & $\begin{array}{l}\text { - Difficulty paying attention for } \\
\text { periods longer than } 10 \text { minutes- } \\
\text { this is pronounced when fatigued } \\
\text { - Social anxiety } \\
\text { - Fear of failure } \\
\text { - Poor rote memory } \\
\text { - Cannot always communicate his } \\
\text { desires and needs effectively }\end{array}$ \\
\hline & Skill Deficits & $\begin{array}{l}\text { - Missing social skills } \\
\text { - Missing problem-solving skills }\end{array}$ \\
\hline \multicolumn{2}{|c|}{$\begin{array}{l}\text { (Biological) Medical or Mental Health } \\
\text { Diagnoses }\end{array}$} & $\begin{array}{l}\text { - Language disorder } \\
\text { - ADHD, predominantly inattentive } \\
\text { type } \\
\text { - Epilepsy } \\
\text { - Periodic insomnia } \\
\text { - Sensory impairments }\end{array}$ \\
\hline
\end{tabular}

Modified from the Multimodal Contextual Behavior Analytic Worksheet: D.M Griffiths, W.I Gardner, \& J.A. Nugent (1998). Behavioral supports: Individual centered interventions - A multimodal functional approach. Kingston, NY: NADD Press.

Reinforcing conditions. The likelihood of the student displaying challenging behaviour is further influenced by the consequences that arise after the behaviour has occurred. Consequences that increase the likelihood of the behaviour occurring are described as reinforcing conditions. Consequences that increase the likelihood of the behaviour occurring when something is added to the environment are positive reinforcers. Consequences that increase the likelihood of the behaviour occurring when something is removed from the environment are negative reinforcers. For example, consider the planned consequence for Adam, the child discussed, if he were to be removed from the classroom (sent to the office) each time he hit another student. This consequence may be reinforcing the hitting behaviour (if Adam is trying to avoid having to complete his work), making the removal from class a negative reinforcer. On the other hand, if an unplanned consequence is that the children in the class laugh at 
the situation (and Adam enjoys being the class clown), then this addition to the situation (laughing) is a positive reinforcer. The teacher will have to manage these reinforcers (both positive and negative) in order to extinguish the hitting behaviour.

\section{Table 3}

\section{Sample Multimodal Profile for Reinforcing Conditions}

(Positive and Negative)

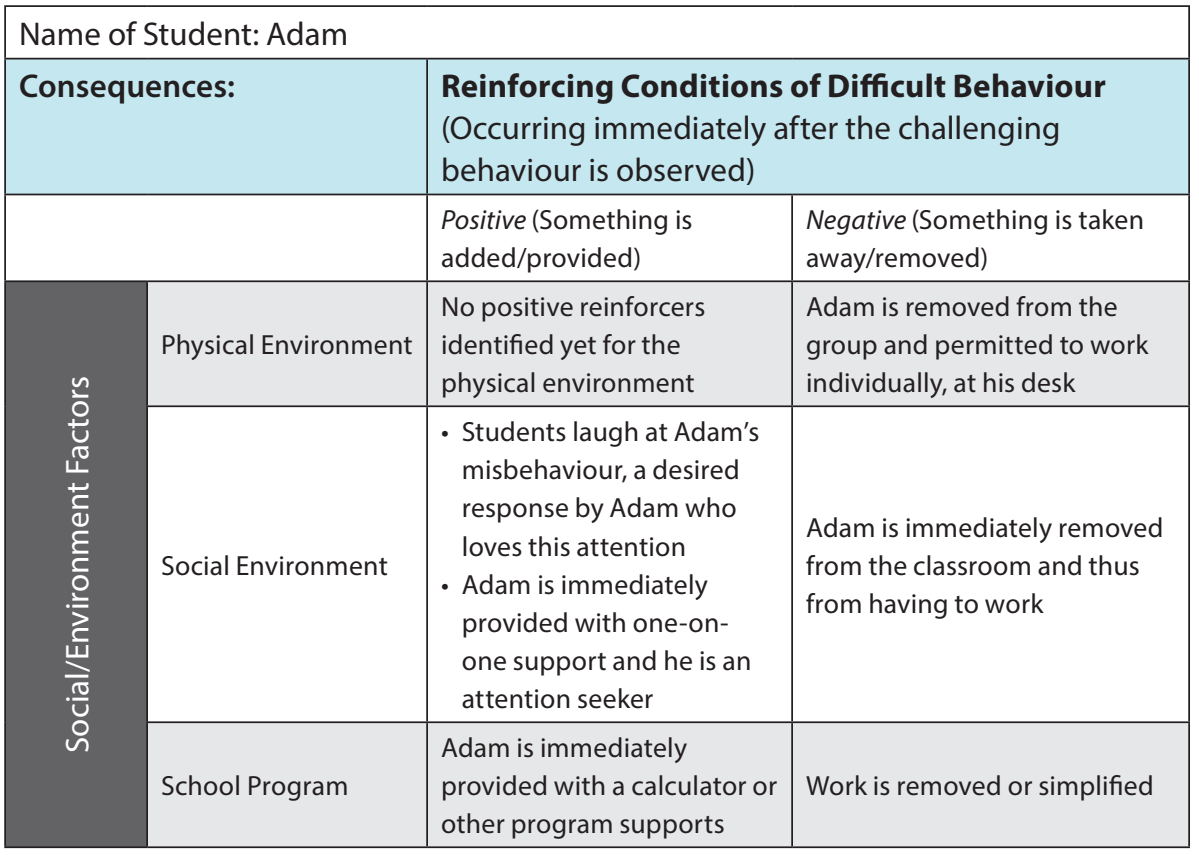

Modified from the Multimodal Contextual Behavior Analytic Worksheet: D.M Griffiths, W.I Gardner, \& J.A. Nugent (1998). Behavioral supports: Individual centered interventions - A multimodal functional approach. Kingston, NY: NADD Press.

Challenging behaviour is influenced by the dynamic interplay among instigating factors (triggers and contributing), vulnerability factors (psychological and biological/ medical), and reinforcing factors. Let's again consider the child, Adam who has challenging behaviour (e.g., hitting) discussed throughout the text, and use his multimodal profile grid (displayed in Tables 1-3) to examine how a teacher may proceed to engineer this particular student's environment and program his day-to-day schoolwork. The multimodal grid, once complete, acts as a checklist of things for the teacher to do to prevent the difficult-to-manage behaviour from occurring. Often teachers are aware of some of the factors in the multimodal grid but have never completed a full multimodal profile, which considers the interplay between each factor. 
Regarding reinforcing conditions. For preventive purposes, the teacher might first remove all negative and positive reinforcing conditions that are sustaining Adam's difficult-to-manage behaviours. She would likely begin by working to prevent the children from laughing at the student's hitting behaviour by applying unwanted consequences. She might then apply planned consequences for the misbehaving child within the classroom (instead of reinforcing the desire not to work by sending him out of the class), and she would likely apply appropriate classroom supports as preventative measures before the behaviour occurred. Her decisions would be made by examining Adam's multimodal profile, which outlines Adam's needs and also what sustains the hitting behaviour.

Next, Adam's teacher might examine how the biological, psychological, and social/ environmental conditions are interacting with each other by again examining the multimodal profile (refer to Tables 1-3). If necessary, the teacher could initially request support from the resource teacher, psychologist, and/or school consultant, depending on the severity of the challenging behaviours and the complexity of the multimodal profile. For example, Adam's multimodal profile indicates that he has a diagnosis of ADHD and without frequent breaks, his challenging behaviour is triggered. His teacher might choose to structure his day to include several planned work breaks. These breaks could include handing out papers, collecting work, and cleaning the board or delivering notes to other teachers, in order to combat the child's difficulty paying attention for long periods. Given other aspects of Adam's profile (refer to Tables 1-3), his teacher would need to ensure that any work requested was well matched to his cognitive level and presented in a manner that is not visually overwhelming. Adam's profile indicates that he has a language disorder that affects his ability to communicate effectively. This may be an additional reason why he does not enjoy working in groups. He may require extra support in getting his ideas across to his classmates. The teaching of skills that Adam is lacking (i.e., social skills and problem-solving skills) could also be based on the multimodal profile, as these skill deficits contribute to Adam's misbehaviour.

Mathematic teaching objectives would likely be related to Adam's problem-solving skills deficit. A calculator could be provided for individual work, based on Adam's difficulty with rote memory, clearly outlined in his profile (Tables 2-3). It is clear the child has social anxiety, which is related to a delay in social development, and thus in his repertoire of social skills. This is not uncommon for children with significant difficulties maintaining their attention. A plan for social skills learning should be made in conjunction with Adam's parents and the teaching team of the child. Within the classroom, the teacher could facilitate Adam's social-skills deficit by managing how group work is completed in class, perhaps by providing appropriate roles to students, 
based on their individual profiles of strengths and weaknesses (also facilitating differentiated instruction).

\section{Regarding social/environmental conditions (triggers and contributing factors).} The teacher would also have to act "on the spot" to change aspects of the environment, if contributing factors were evident. We know that for Adam these factors include being fatigued, having to work close to other students when concentration is required, working in groups, using worksheets that are visually "busy," and completing math work without a calculator (indicated on Table 1). Therefore, if Adam arrived at school looking fatigued (see Table 2; Vulnerability Factors, which indicates he has periodic insomnia), all other contributing factors, such as having to work close to another student during more difficult work assignments or participating in group work, would not be possible that day. Knowing the contributing factors would significantly reduce behaviours: First, by knowing when the student is particularly vulnerable to having challenging behaviour. Second, by knowing which factors must be eliminated when the student is vulnerable. Removing all triggers (conditions that always lead to challenging behaviour) in this case, working with students who have imposing personalities, would imply a particular seating arrangement and avoiding group work with these types of students on a daily basis.

Regarding psychological conditions. Adam's multimodal profile (Table 2; Vulnerability Factors) indicates that he has, among other factors, social anxiety, poor rote memory, and a fear of failure. In consideration of this psychological profile, once the initial classroom engineering was completed, the teacher might choose to incorporate a program wherein each classroom lesson ended with five minutes devoted to the teaching of how mistakes lead to better products and increased learning. The teacher could discuss examples from the particular lesson to support the generalization of how failure is not the result of making mistakes. Such a program (which would require only minimal extra planning time) would benefit all students and would be worth the effort for this particular student whose fear of failure contributes to his challenging behaviour.

With time and, in some cases, initial support from a specialist or professional, a teacher could provide an environment that is a "best fit" for even the most challenging of students. Realistically, this would not mean that the child, for whom the multimodal profile was created, would no longer have difficult-to-manage behaviours. Instead, a large number of the behaviours could be prevented. Remaining behaviours could be explored in a functional behavioural analysis (FBA), an expected process for teachers to follow when they are stumped by a behaviour that a student is exhibiting. 
A functional behavioural analysis, developed in the field of behavioural psychology, employs fundamental principles of operant conditioning in order to determine the reason why particular behaviour is persisting. The goal of such an analysis is to make hypotheses about the purpose or motivation for a behaviour and then to test the hypothesis. If the hypothesis is correct, the behaviour will cease once the motivation or reason for the behaviour is removed.

Table 4

Functional Behavioural Analysis Grid for Targeted Behaviours

\begin{tabular}{|l|l|l|}
\hline $\begin{array}{l}\text { Name: } \\
\text { Date: }\end{array}$ & \multicolumn{2}{|l|}{$\begin{array}{l}\text { Functional Behavioural Analysis Grid } \\
\text { for Targeted Behaviours }\end{array}$} \\
\hline Describe Behaviour Targeted & $\begin{array}{l}\text { Trial \# 1 } \\
\text { Name Behaviour: }\end{array}$ & $\begin{array}{l}\text { Trial \# 2 } \\
\text { Name Behaviour: }\end{array}$ \\
\cline { 2 - 3 } & & \\
\hline Desired Objective & & \\
\hline $\begin{array}{l}\text { Hypotheses (Reasons why } \\
\text { you think the behaviour } \\
\text { is occurring or is being } \\
\text { reinforced) }\end{array}$ & & \\
\hline $\begin{array}{l}\text { Trial Plan } \\
\text { (Description of the trial plan } \\
\text { and date of completion) }\end{array}$ & & \\
\hline Person Responsible & & \\
\hline $\begin{array}{l}\text { Was the Plan a } \\
\text { Success? }\end{array}$ & & \\
\hline Report Measureable Results & & \\
\hline
\end{tabular}

To establish the function of a behaviour, the following must be identified: any triggers of the behaviour, any aspects of the student that influence or feed into the behaviour, and any consequences of the behaviour which are reinforcing the behaviour. All of this information is available in the multimodal profile of the student. Not having a multimodal profile for a student with persistent, difficult-to-manage behaviours makes any attempt to reshape or eliminate behaviours more like a guessing game. Each incorrect guess can have disastrous consequences for the teacher. Most teachers have a large "tool box" of strategies to manage difficult behaviours. What they don't have is a method or formula for matching the strategies to the child or to the behaviour. Not all strategies for ADHD, for example, will work for all children with ADHD. Success rates for any strategy depend on the student's individual multimodal profile. The reasons 
why behaviours are occurring supersede any diagnostic label that the child may have been given. A diagnostic label is just not enough information to build an individual behavioural plan. This is well known in psychological circles, but the information has not been fluid between the disciplines.

There is strong theoretical and clinical support for the building of multimodal profiles that have a biopsychosocial approach for students with chronically challenging behaviours. Using such a plan, a teacher would be more confident in making hypotheses about why challenging behaviour is occurring and thus could be more accurate in solving behaviour problems. Additionally, any new causes of behaviour discovered during a functional behavioural analysis could be added to the multimodal profile. The idea is that the base profile is created only once, and only for students with chronic behaviour problems. As the teacher gleans new information, the multimodal profile is updated and continuously strengthens the ability of the teacher to manage the student's environment, and also to program his or her individual plan in a preventative and holistic manner. The teacher is in a position to better use her well-developed "tool box" of strategies for challenging behaviour, by having an improved ability to match her strategies to the reasons why problem behaviour is occurring in her classroom.

\section{Conclusion}

Just as education borrowed from the field of developmental psychology to support curriculum development, and, in turn psychology borrowed from the field of education by incorporating Gardner's (1983) proposed "intelligences" into the building of clinical learning profiles, we need to continue to keep knowledge between the disciplines fluid. Both disciplines should continue to influence each other and thus bring true meaning to the development of educational psychology. 


\section{References}

Engel, G.L. (1977). The need for a new medical model: a challenge for biomedicine, Science, 196, 129-136. doi:10.1126/science.847460.

Engel, G.L. (1980). The clinical application of the biopsychosocial model. American Psychiatry, 137, 535-544. Retrieved from: http://ajp.psychiatryonline.org/article. aspx?articleid $=158186$

Gardner, H. (1983). Frames of mind: The theory of multiple intelligences. New York: Basic Books.

Griffiths, D. M., \& Gardner, W. I. (2002). The integrated biopsychosocial approach to challenging behaviours. In D. M. Griffiths, C. Stavrakaki, \& J. Summers (Eds.), Dual diagnosis: An introduction to the mental health needs of persons with developmental disabilities (pp. 81-114). Sudbury, ON: Habilitative Mental Health Resource Network.
Griffiths, D. M., Gardner, W. I., \& Nugent, J.A. (1998). Behavioural supports: Individual centered interventions - A multimodal functional approach. Kingston, NY: NADD Press.

Grinker, Sr RR. (1964). A struggle for eclecticism. American Journal of Psychiatry, 121, 451-457. Retrieved from: http://ajp.psychiatryonline. org/article. aspx?articleid=149749

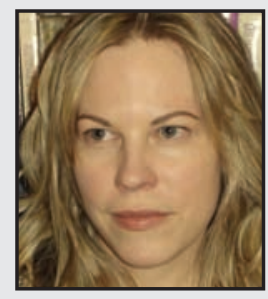

Lisa Reisinger is a psychologist, educational speaker, internationally published author, and former elementary school teacher and university lecturer. She has been supporting teachers and professionals for students with special needs for over 20 years. Currently she is working at the West Montreal Readaptation Centre where she is a clinical leader and psychologist for children, teens, and adults with severe challenging behaviours. She is a specialist for individuals with autism spectrum disorder and intellectual disabilities.

\section{LINK TO:}

